\title{
Towards Epoxidation Catalysts for Fluorous Biphase Systems: Synthesis and Properties of Two Mn(III)-Tetraarylporphyrins Bearing Perfluoroalkylamido Tails.
}

\author{
Gianluca Pozzi *, Stefano Banfi, Amedea Manfredi, Fernando Montanari and Silvio Quici. \\ Centro CNR and Dipartimento di Chimica Organica e Industriale dell'Università \\ Via Venezian 21, 1-20133 Milano, Italy
}

\begin{abstract}
Two new Mn(III)-tetraarylporphyrins $\mathrm{Mn-1}$ and $\mathrm{Mn-2}$ bearing one amido-bonded $n$ $\mathrm{C}_{7} \mathrm{~F}_{15}$ chain on each meso-aryl group have been synthesized. The presence of four perfluoroalkyl tails strongly influences the solubility of these compounds in common organic solvents, but it is not sufficient to impart solubility in fluorocarbons. The catalytic activity of the new complexes was tested in alkene epoxidations employing aqueous $\mathrm{NaOCl}$ as oxygen donor. Results show that $\mathrm{Mn-2}$ is more active than Mn(III)-5,10,15,20-tetrakis-(2,6-dichlorophenyl)porphyrin, one of the most efficient porphyrinic catalysts for hydrocarbon oxygenation.

Copyright $\mathcal{1} 1996$ Published by Elsevier Science Ltd
\end{abstract}

Fluorocarbons (perfluorinated alkanes, ethers and tertiary amines) have peculiar chemical and physical properties which are potentially exploitable in many technological fields. ${ }^{1}$ Advantages in using these compounds as inert media for chemical reactions (e.g. esterification, ${ }^{2}$ photolysis, ${ }^{3}$ bromination of alkenes ${ }^{4}$ and oxidation of organozincs to hydroperoxides ${ }^{5}$ ) have been pointed out. A new approach to liquid biphasic catalytic reactions based on the low miscibilities of fluorocarbons with most organic solvents has been recently described by Horváth and Rábai. ${ }^{6}$ In what these authors define as "Fluorous Biphase System" (FBS) the catalyst is confined to the fluorocarbon phase, whereas substrate/s and product/s are dissolved in a common organic solvent. Reactions can be carried out in the resulting biphasic system, but it is also possible to work under homogeneous conditions by increasing the temperature. At the end of the reaction the catalyst can be easily recovered, after cooling, by simple phase separation and it becomes at once available for further use. Despite the opportunities offered, this approach has been applied only to hydroformylation of olefins: extension to other reactions calls for the availability of efficient "ad hoc" catalysts soluble in fluorocarbons. Insertion of perfluoroalkyl segments in the structure of known active compounds has been proposed as a general solution for the problem, ${ }^{6}$ but, despite apparent simplicity, concrete application of this strategy is still a challenge.

Hydrocarbon oxygenation is a highly attractive field for application of the FBS concept. Therefore we are currently engaged in a program aimed at the synthesis of catalysts that will serve this purpose. In this article we describe the synthesis of two tetraarylporphyrins 1 and 2 (Fig. 1) bearing perfluoroalkyl chains linked to the meso-aryl groups through amido bonds. Against all expectations, this feature is not sufficient to impart solubility in fluorocarbons; still the Mn(III)-complexes of the new compounds (Mn-1, Mn-2) show interesting properties 
as catalysts for alkene epoxidation in aqueous/organic biphasic systems, related to the presence of the perfluoroalkyl tails.

Fig. 1. Structure of porphyrins 1-3 and 8 .

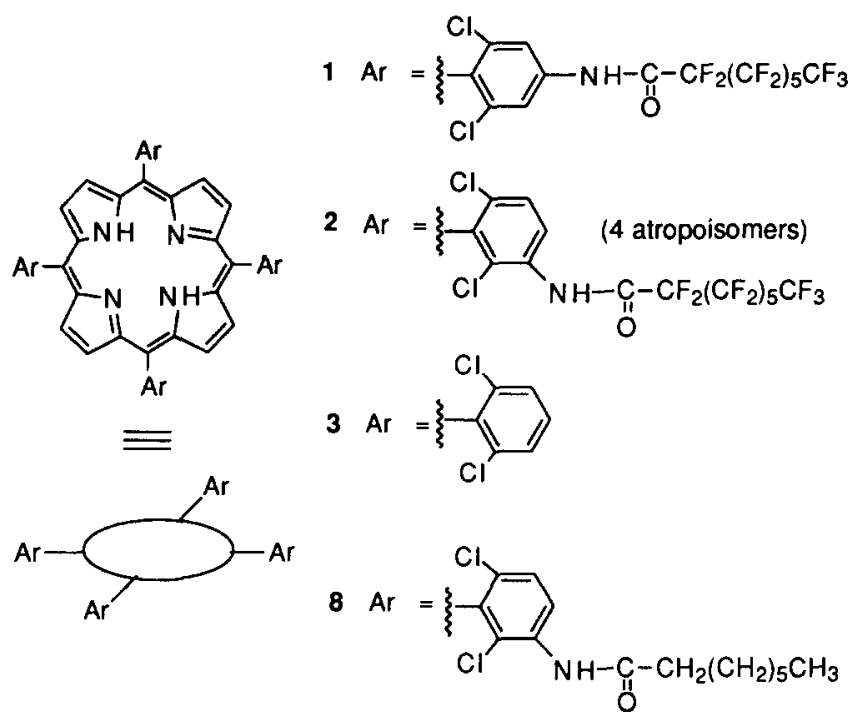

\section{RESULTS AND DISCUSSION}

Our choice of Mn(III) complexes of porphyrins 1 and 2, two analogues of the robust 5,10,15,20-tetrakis(2,6-dichlorophenyl)porphyrin 3, as possible fluorocarbon soluble catalysts for hydrocarbon oxygenation was based on the following premises.

Metallo-tetraarylporphyrins are well-known catalysts for hydrocarbon oxygenation. ${ }^{7}$ The functionalization of the macrocyclic ligand by linking perfluoroalkyl tails was reasonably expected to impart fluorophilic character to this class of compounds. Furthermore, the introduction of strong electron-withdrawing perfluoroalkyl chains $\left(\mathrm{R}_{\mathrm{F}}\right)$ could alter the electronic properties of the complexes and it should favourably affect their stability and catalytic efficiency. The presence of electron-withdrawing groups on the meso-aryl substituents and/or in the $\beta$ pyrrolic positions leads to electron-poor porphyrins which should be protected from oxidative decomposition. ${ }^{8}$ In a recent communication, metal complexes of highly electron-deficient meso-perfluoroalkyl substituted porphyrins were found to be able to catalyse the oxidation of isobutane to tert-butyl alcohol. ${ }^{9}$ It is worthwile to stress that experimental ${ }^{10}$ and computational ${ }^{11}$ studies cast some doubt on the asserted positive consequences of the $\beta$-substitution, which can also results in severe nonplanar distorsion of the macrocycle ${ }^{12}$.

Stability as well as catalytic efficiency of metallo-tetraarylporphyrins under oxidative conditions are governed by both electronic and steric effects. ${ }^{13}$ Only two examples of perfluoroalkyl-substituted tetraarylporpyrins $(5,10,15,20$-tetrakis-(4-trifluoromethylphenyl)porphyrin 8 and 5,10,15,20-tetrakis-(2trifluoromethylphenyl)porphyrin ${ }^{14}$ ) have been reported in the open literature. These compounds are not soluble 
in fluorocarbons and they suffer from lack of steric protection against $\mu$-oxo dimerization and other undesired side-reactions. In our experience, the complete substitution of the ortho hydrogen atoms of the meso-aryl groups with chlorine is a key factor for achieving the required resistance of the catalysts under oxidative conditions.

Although tailed porphyrins containing ether bonds are more stable than those featuring amido bonds, 15 the latter kind of connection was preferred because of its easier synthesis. We also decided to tether the perfluoroalkyl chains to preformed tetraarylporphyrins instead of using perfluoroalkylated building blocks. Indeed, the presence of $\mathrm{R}_{\mathrm{F}}$ residues can be troublesome for most cyclisation procedures and it can lower considerably the yields in the desired porphyrin. ${ }^{14,16}$

Tetraarylporphyrins 1 and 2 were synthesized following the pathway outlined in Scheme 1.

Scheme 1. Synthesis of porphyrins 1 and 2.
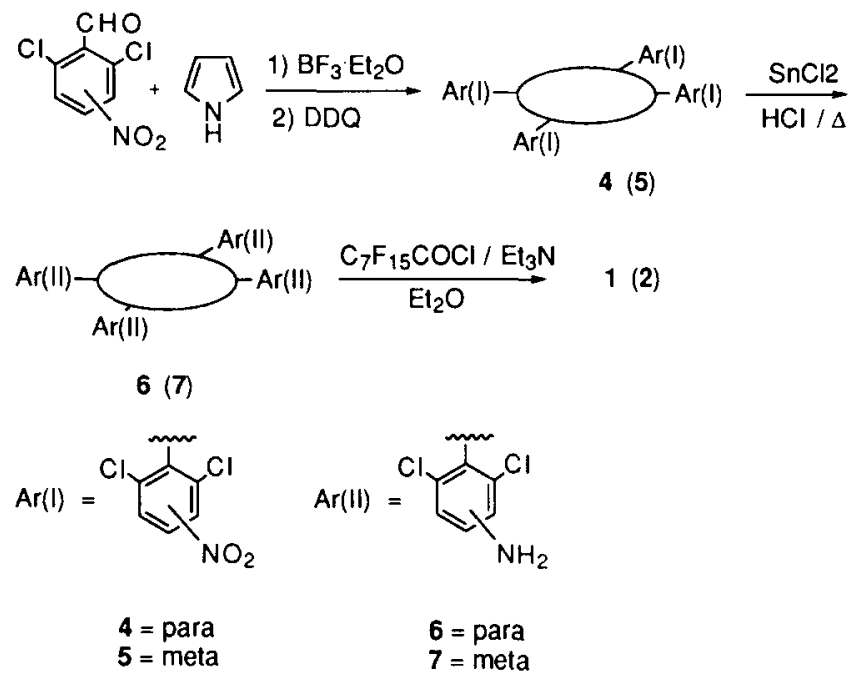

Porphyrin 6 and 7, bearing four amino groups at the para and meta positions of the four meso-aryl substituents respectively, were prepared by condensation of the appropriate 2,6-dichloro-nitrobenzaldehyde with pyrrole ${ }^{14}$ followed by reduction of the nitro groups with $\mathrm{SnCl}_{2} / \mathrm{HCl}$. Because of the hindered rotation of the aryl groups, due to the presence of the ortho-chlorine atoms, 7 was obtained as a mixture of four atropoisomers. All attempts to isolate the single isomers failed and the porphyrin was used as such for the further functionalization, carried out by treating a suspension of the macrocycle in ether with a large excess of $n-\mathrm{C}_{7} \mathrm{~F}_{15} \mathrm{COCl}$ in the presence of Et3N. The yield of the perfluoroacylation step was only $40 \%$ in the case of 1 , while it was $80 \%$ for 2. This large difference matches the different solubility of the final products in ether (Table 1) which is lower for 1 .

Mass spectrometry showed that the convertion of both tetraarylporphyrins into their $\mathrm{Mn}$ (III) complexes by addition of an excess of $\mathrm{Mn}(\mathrm{OAc}) 2 \cdot 4 \mathrm{H}_{2} \mathrm{O}$ to a refluxing DMF solution of the ligand 17 was accompanied by partial hydrolysis of the amido bonds. Instead of trying to separate the various products, the crude complexes were treated again with an excess of $n-\mathrm{C}_{7} \mathrm{~F}_{15} \mathrm{COCl}$ thus leading to complete perfluoroacylation of all the amino 
groups. The overall yields of the metalation/perfluoroacylation steps in the syntheses of $\mathrm{Mn}-1, \mathrm{Mn}-2$ were $36 \%$ and $74 \%$ respectively.

Dealing with 1 and 2 , we soon recognised that the solubility of the two compounds differs widely. The presence of four perfluoroalkyl tails is not sufficient to make 1 and 2 soluble in fluorocarbons, but while the latter porphyrin is easily dissolved in most organic solvents at concentrations $\leq 10^{-3} \mathrm{M}, \mathbf{1}$ is sparingly soluble only in AcOEt, DMF and ethers (Table 1). These trends applies also to the respective $\mathrm{Mn}$ (III)-complexes.

Table 1. Solubility of Porphyrins 1 and $2 a$ in Organic Solvents at $20^{\circ} \mathrm{C}$.

\begin{tabular}{ccc}
\hline Solvent & 1 & 2 \\
\hline $\mathrm{CCl}_{4}$ & insoluble & soluble \\
$\mathrm{CHCl}_{3}$ & insoluble & soluble \\
$\mathrm{CH}_{2} \mathrm{Cl}_{2}$ & insoluble & soluble \\
$\mathrm{CF}_{2} \mathrm{ClCCl}_{2} \mathrm{~F}$ & insoluble & soluble \\
$\mathrm{CH}_{3} \mathrm{CN}$ & slightly soluble & soluble \\
$\mathrm{DMF}^{b}$ & slightly soluble & soluble \\
$\mathrm{AcOEt}$ & slightly soluble & soluble \\
$\mathrm{C}_{6} \mathrm{H}_{6}$ & insoluble & soluble \\
$\mathrm{C}_{6} \mathrm{H}_{5} \mathrm{Cl}$ & insoluble & soluble \\
$\mathrm{c}-\mathrm{C}_{6} \mathrm{H}_{12}$ & insoluble & slightly soluble \\
$\mathrm{MTBE}$ & slightly soluble & soluble \\
$\mathrm{DME}$ & slightly soluble & soluble \\
$\mathrm{E}_{2} \mathrm{O}$ & slightly soluble & soluble \\
\hline
\end{tabular}

$a_{\text {[Porphyrin] }}=10^{-3} \mathrm{M}$. Both porphyrins are insoluble in FC-72 (mainly perlluorohexanes), FC-77 (mainly perfluoro-(2-nbutyltetrahydrofuran) and FC-43 (mainly $\left(n-\mathrm{C}_{4} \mathrm{Fg}\right){ }_{3} \mathrm{~N}$. ${ }^{b}$ Soluble at reflux. ${ }^{c}$ Soluble at []$=10^{-4} \mathrm{M}$.

The behaviour of 1 fits in with the decrease in solubility expected from incorporation of four amido linkages. Moreover perfluoroalkylanilides are prone to aggregation in organic solvents even at very low concentration. ${ }^{18}$ Ethers are among the few good solvents for perfluoroalkyl derivatives and the unusual solubility of tetraarylporphyrins 1 and 2 in Et2O, DME and $t$-butyl methyl ether (MTBE) can be ascribed to the favourable interaction of these solvents with the RF tails. ${ }^{19}$ The remarkable high solubility of $\mathbf{2}$ in a wide range of solvents is related to the low degree of symmetry of this compound which in addition was synthesized as a mixture of atropoisomers. In this case too, ethers were found to be good solvents and, rather interestingly, even cyclohexane is able to solubilize 2 at low concentration.

Catalytic activity of $\mathrm{Mn}-1$ and $\mathrm{Mn}-2$ was tested in the epoxidation of two model compounds, cyclooctene and 1 -dodecene, which are representative of easily oxidised and poorly reactive $\alpha$-olefins respectively. Reactions 
were carried out at $0^{\circ} \mathrm{C}$ under aqueous/organic two-phase conditions, using $\mathrm{NaOCl}$ as oxygen donor in the presence of $\mathrm{N}$-hexylimidazole as axial ligand for the $\mathrm{Mn}$ complexes. The $\mathrm{pH}$ of the aqueous solution was adjusted to 10.0 with solid $\mathrm{NaHCO}_{3}$ before starting the reaction. 20 Yields obtained (determined by gaschromatographic analysis of the organic phase) are shown in tables 2 and 3.

Table 2. Alkene Epoxidations by $\mathrm{HOCl} / \mathrm{OCl}^{-}$: Comparison between Catalysts $\mathrm{Mn-1}$ and $\mathrm{Mn}-2 .{ }^{a}, b$

\begin{tabular}{rllccc}
\hline Catalyst (P) & Olefin (S) & Solvent & Time (min) & Yield $^{c}(\%)$ & ${\mathrm{A} / \mathrm{A}_{0}{ }^{d}(\%)}^{(24}$ \\
\hline Mn-1 & Cyclooctene & MTBE & 30 & 22 & 78 \\
Mn-2 & Cyclooctene & MTBE & 30 & 24 & 95 \\
Mn-1 & Cyclooctene & AcOEt & 60 & 38 & 40 \\
Mn-2 & Cyclooctene & AcOEt & 60 & 65 & 95 \\
Mn-1 & 1-dodecene & AcOEt & 240 & 22 & 32 \\
Mn-2 & 1-dodecene & AcOEt & 240 & 35 & 50 \\
\hline
\end{tabular}

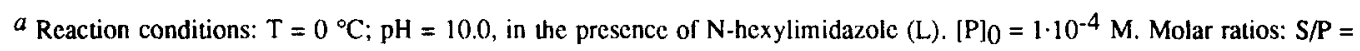
$1000, \mathrm{~L} / \mathrm{P}=2 ; \mathrm{NaOCl} / \mathrm{S}=3 .^{b}$ Average values over 3 runs. ${ }^{c}$ Determined by gas-chromatographic analysis of the organic phase. $d \mathrm{UV}$-Vis Absorbance of the organic layer at $478 \mathrm{~nm}$.

Both ethers and AcOEt are able to dissolve $\mathrm{Mn}-1$ and $\mathrm{Mn}-2$ at concentration $=10^{-4} \mathrm{M}$, but preliminary experiments on cyclooctene showed that MTBE, the most attractive ether, was unsuitable as the organic phase. Reactions carried out in MTBE afforded low yields in epoxide. Moreover the catalytic activity of both complexes came to an end in only $30 \mathrm{~min}$, when catalyst concentration (evaluated by the intensity of the UV-Vis absorbance of the organic layer at $478 \mathrm{~nm}$ ) was still in the order of $80-90 \%$ of the initial value. The reasons for this behaviour are not clear. Competition between ether oxygen and $\mathrm{N}$-hexylimidazole for the axial coordination to the $\mathrm{Mn}^{\mathrm{n}+}$ species can be ruled out as the cause of the low catalytic activity of the two complexes. Indeed for reactions carried out in AcOEt, where the same competition is possible, alkene conversions were definitely higher. In the case of $\mathrm{Mn-2}$, conversions were even higher than those obtained running epoxidations in a noncoordinating solvent as $\mathrm{CH}_{2} \mathrm{Cl}_{2}$ (Table 3). Water solubility in MTBE is lower than in AcOEt so that transfer of $\mathrm{HOCl} / \mathrm{OCl}^{-}$from the aqueous phase to the organic one could be hindered. The low concentration of the oxygen donor in the organic solvent could justify the decrease of epoxidation rate, but not the observed stop of the reactions after 200-250 catalytic cycles.

In order to compare the catalytic efficiency of $\mathrm{Mn}-1$ and $\mathrm{Mn}-2, \mathrm{AcOEt}$ was then used as the organic phase. It is evident from our results that $\mathrm{Mn-1}$ is a poor catalyst with respect to $\mathrm{Mn}-2$, thus confirming that the introduction of amido linkages in the para position of the meso-aryl groups has a definite negative effect on the catalytic activity of tailed $\mathrm{Mn}$ (III)-porphyrins. 15

In the case of Mn-2 the electronwithdrawing action of four RF tails counterbalances the less pronounced negative effect of the meta-amido bonds, as shown by comparison between this catalyst and $\mathrm{Mn}-3$ (Table 3 ). 
Table 3. Alkene Epoxidations by $\mathrm{HOCl} / \mathrm{OCl}^{-}$: Comparison among Catalysts $\mathrm{Mn}-2, \mathrm{Mn}-3$ and $\mathrm{Mn}-8$.

\begin{tabular}{ccccc}
\hline Catalyst (P) & Olefin (S) & Time (min) & Yield $c(\%)$ & $\mathrm{A}^{\prime} \mathrm{A}_{0}{ }^{d}(\%)$ \\
\hline $\mathrm{Mn-2}$ & Cyclooctene & 120 & 82 & 60 \\
$\mathrm{Mn-3}$ & Cyclooctene & 120 & 84 & 58 \\
$\mathrm{Mn-8}$ & Cyclooctene & 120 & 25 & 34 \\
$\mathrm{Mn}-2$ & 1-dodecene & 180 & 33 & 53 \\
$\mathrm{Mn}-3$ & 1-dodecene & 180 & 21 & 75 \\
$\mathrm{Mn}-8$ & 1-dodecene & 180 & 9 & 10 \\
\hline
\end{tabular}

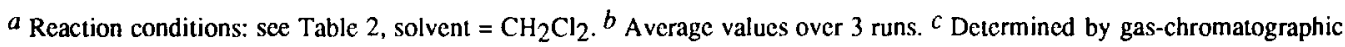
analysis of the organic phase. ${ }^{d} \mathrm{UV}$-Vis Absorbance of the organic layer at $478 \mathrm{~nm}$.

The two complexes gave similar results in the epoxidation of cyclooctene carried out in $\mathrm{CH}_{2} \mathrm{Cl}_{2}$. Catalyst $\mathrm{Mn}-2$ was even more active than $\mathrm{Mn-3}$ in the epoxidation of the poorly reactive 1-dodecene. The effectiveness of the perfluoroalkylated catalyst can be better appraised in the light of the experiments performed with its hydrogenated analogue Mn-8 (Fig. 1). ${ }^{21}$ Reactions catalysed by Mn-2 showed higher substrate conversions and increased reaction rates in comparison with those carried out in the presence of $\mathrm{Mn-8}$. Moreover, the yields in epoxide obtained with the latter catalyst were always lower than those obtained with $\mathrm{Mn}-\mathbf{3}$, thus evidencing the weak spot represented by the amido bonds.

\section{CONCLUSIONS}

The present results show that the insertion of four perfluoroalkyl tails does influence the solubility of $\mathrm{Mn}$ (III)-tetraarylporphyins and their catalytic activity. The location of the RF substituents on the meso-aryl groups strongly affects the behaviour of these compounds, at least in the case of tails tethered through amido bonds. Despite the partial inadequacy of this kind of connection, high turnovers were obtained using Mn-2. These encouraging findings stimulate us to further efforts towards the synthesis of similar compounds for which the $\mathrm{F} / \mathrm{C}$ ratio will be even higher and the $\mathrm{RF}_{\mathrm{F}}$ tails will be directly linked to the meso-aryl groups. We hope that these two features will allow to exploit the beneficial effect of the RF substituents in Fluorous Biphase Systems. 


\section{EXPERIMENTAL SECTION}

UV-VIS spectra were measured using a Lambda 6 Perkin-Elmer spectrometer in $\mathrm{Et}_{2} \mathrm{O}$ or $\mathrm{CH}_{2} \mathrm{Cl}_{2}$ solution. ${ }^{1} \mathrm{H}$-NMR and ${ }^{19} \mathrm{~F}$-NMR spectra were recorded on a Varian XL 300 spectrometer with tetramethylsilane $(\delta=0)$ and $\mathrm{CFCl}_{3}(\delta=0)$ as internal standard respectively. Mass spectra were obtained using an Analytical VG 7070 EQ spectrometer. GC analyses were performed on Varian Model 3700 ( $20 \times 0.125$ in. OV-101-5\% on CHP 100125 mesh column) and Hewlett-Packard 5890 (30 x $0.5 \mathrm{~mm}$ RSL-200 polymethylsiloxane column) gas chromatographs. All the commercially available reagents were used as received; solvents for column chromatography were distilled over $\mathrm{CaCl}_{2}$ before the use. $\mathrm{CH}_{2} \mathrm{Cl}_{2}$ used in porphyrin syntheses was a "Baker analyzed" reagent $(0.01 \%$ of water) stabilized with amylene.

5,10,15,20-tetrakis-(2,6-dichloro-4-nitrophenyl)porphyrin (4). A solution of 2,6-dichloro-4nitrobenzaldehyde $22(2.21 \mathrm{~g}, 10 \mathrm{mmol})$, pyrrole $(0.67 \mathrm{~g}, 10 \mathrm{mmol})$ and $\mathrm{BF}_{3} \cdot \mathrm{Et}_{2} \mathrm{O}(0.47 \mathrm{~g}, 3.3 \mathrm{mmol})$ in $\mathrm{CH}_{2} \mathrm{Cl}_{2}(1000 \mathrm{ml})$, was stirred at $\mathrm{rt}$ for $15 \mathrm{~h}$. After addition of 2,3-dichloro-5,6-dicyano-1,4-benzoquinone $(1.51 \mathrm{~g}, 6.7 \mathrm{mmol})$ the reaction mixture was stirred for $2 \mathrm{~h}$, then $\mathrm{Et}_{3} \mathrm{~N}(1 \mathrm{ml})$ was added and the solvent evaporated. The residue was supported on Florisil ( $20 \mathrm{~g}$ ) and purified by column chromatography (silica-gel, $\mathrm{CH}_{2} \mathrm{Cl}_{2}$ /light petroleum 4/1) The slightly impure porphyrin was dissolved in $\mathrm{CH}_{2} \mathrm{Cl}_{2}(10 \mathrm{ml})$ and reprecipitated by adding $n$-pentane affording pure product $(0,74 \mathrm{~g}$, yield $=28 \%),{ }^{1} \mathrm{H} \mathrm{NMR}\left(\mathrm{CDCl}_{3}\right) \delta=-2.55(\mathrm{~s}, 2 \mathrm{H}), 8,63$ (s, 8H), $8.68(\mathrm{~s}, 8 \mathrm{H}) ; \mathrm{UV}-\mathrm{Vis}\left(\mathrm{CH}_{2} \mathrm{Cl}_{2}\right) \lambda_{\max }(\log \varepsilon)=420 \mathrm{~nm}(5.45) ; \mathrm{MS}\left(\mathrm{FAB}^{+}\right) \mathrm{m} / \mathrm{z} 1071$; Anal. Calcd for $\mathrm{C}_{44} \mathrm{H}_{18} \mathrm{Cl}_{8} \mathrm{~N}_{8} \mathrm{O}_{8}: \mathrm{C}, 49.38 ; \mathrm{H}, 1.70 ; \mathrm{N}, 10.46$. Found: $\mathrm{C}, 49.02 ; \mathrm{H}, 2.02 ; \mathrm{N}, 10.40$.

5,10,15,20-tetrakis-(2,6-dichloro-3-nitrophenyl)porphyrin (5). This compound was synthesized starting from 2,6-dichloro-3-nitrobenzaldehyde according to the procedure described for 4 (mixture of atropoisomers, yield $=34 \%) .{ }^{1} \mathrm{H} \mathrm{NMR}\left(\mathrm{CDCl}_{3}\right) \delta=-2.60(\mathrm{~s}, 2 \mathrm{H}), 7.95-8.00(\mathrm{~m}, 4 \mathrm{H}), 8.29(\mathrm{~d}, J=8.8 \mathrm{~Hz}, 4 \mathrm{H}), 8.67(\mathrm{br} \mathrm{s}$, $8 \mathrm{H})$; UV-Vis $\left(\mathrm{CH}_{2} \mathrm{Cl}_{2}\right) \lambda_{\max }(\log \varepsilon)=419 \mathrm{~nm}(5.40) ; \mathrm{MS}\left(\mathrm{FAB}^{+}\right) \mathrm{m} / \mathrm{z} 1071$; Anal. Calcd for $\mathrm{C}_{44} \mathrm{H}_{18} \mathrm{Cl}_{8} \mathrm{~N}_{8} \mathrm{O}_{8}: \mathrm{C}, 49.38 ; \mathrm{H}, 1.70 ; \mathrm{N}, 10.46$. Found: $\mathrm{C}, 49.15 ; \mathrm{H}, 1.85 ; \mathrm{N}, 10.28$.

5,10,15,20-tetrakis-(2,6-dichloro-4-nitrophenyl)porphyrin (6). A suspension of porphyrin $4(0.26 \mathrm{~g}$, $0.24 \mathrm{mmol})$ in $36 \% \mathrm{HCl}(20 \mathrm{ml})$ was heated at $60{ }^{\circ} \mathrm{C}$ under vigorous stirring and $\mathrm{SnCl}_{2} \cdot 2 \mathrm{H}_{2} \mathrm{O}(2.26 \mathrm{~g}, 10$ $\mathrm{mmol}$ ) was added to the mixture. After $2 \mathrm{~h}$ the solvent was evaporated under vacuum. The solid residue was placed in a Sohxlet timble and extracted with $\mathrm{CH}_{2} \mathrm{Cl}_{2}$ for $12 \mathrm{~h}$, then the liquid phase was concentrated and filtered through a short bed of silica-gel. Elution was carried out with $\mathrm{CH}_{2} \mathrm{Cl}_{2} / \mathrm{CH}_{3} \mathrm{OH} 98 / 2$. Fractions containing the product were collected together and taken to dryness. The solid residue was dissolved in $\mathrm{CH}_{2} \mathrm{Cl}_{2}$ $(10 \mathrm{ml})$ and reprecipitated by adding $n$-pentane affording the desired amino-substituted porphyrin $(0.21 \mathrm{~g}$, yield $=92 \%$ ). ${ }^{1} \mathrm{H}$ NMR (acetone-d 6$) \delta=-2.46(\mathrm{~s}, 2 \mathrm{H}), 5.52-5.70$ (br s, 8H), $7.25(\mathrm{~s}, 8 \mathrm{H}), 8.87(\mathrm{~s}, 8 \mathrm{H})$; UV-Vis $\left(\mathrm{CH}_{2} \mathrm{Cl}_{2}\right) \lambda_{\max }(\log \varepsilon)=420 \mathrm{~nm}(5.39) ; \mathrm{MS}\left(\mathrm{FAB}^{+}\right) \mathrm{m} / \mathrm{z} 950$; Anal. Calcd for $\mathrm{C}_{44} \mathrm{H}_{26} \mathrm{Cl}_{8} \mathrm{~N}_{8}$ : C, 55.58; $\mathrm{H}$, $2.74 ; \mathrm{N}, 11.79$. Found: $\mathrm{C}, 55.42 ; \mathrm{H}, 2.55 ; \mathrm{N}, 12.05$

5,10,15,20-tetrakis-(2,6-dichloro-3-aminophenyl)porphyrin (7). This compound was synthesized starting from porphyrin 5 according to the procedure described for 6 (mixture of atropoisomers, yield $=75 \%$ ). ${ }^{1} \mathrm{H}$ NMR (DMSO-d 6$) \delta=-2.78(\mathrm{~s}, 2 \mathrm{H}), 5.98-5.83(\mathrm{br} \mathrm{s}, 8 \mathrm{H}), 7.32(\mathrm{~d}, J=8.9 \mathrm{~Hz}, 4 \mathrm{H}), 7.64(\mathrm{~d}, J=8.9 \mathrm{~Hz}, 4 \mathrm{H})$, 
8.68-8.80 (br s, $8 \mathrm{H})$; UV-Vis $\left(\mathrm{CH}_{2} \mathrm{Cl}_{2}\right) \lambda_{\max }(\log \varepsilon)=420 \mathrm{~nm}(5.39)$; $\mathrm{MS}\left(\mathrm{FAB}^{+}\right) \mathrm{m} / \mathrm{z}$ 950; Anal. Calcd for $\mathrm{C}_{44} \mathrm{H}_{26} \mathrm{Cl}_{8} \mathrm{~N}_{8}$ : C, 55.58; $\mathrm{H}, 2.74 ; \mathrm{N}, 11.79$. Found: C, 55.86; H, 2.80; N, 11.41 .

5,10,15,20-tetrakis-[2,6-dichloro-4-(n-perfluorooctacarbamoyl)phenyl]porphyrin (1). To a suspension of porphyrin $6(0.17 \mathrm{~g}, 0.18 \mathrm{mmol})$ and $\mathrm{E}_{3} \mathrm{~N}(0.25 \mathrm{ml}, 1.8 \mathrm{mmol})$ in dry Et2 $\mathrm{O}(10 \mathrm{ml}) n$-perfluorooctanoyl chloride $(0.47 \mathrm{~g}, 1.08 \mathrm{mmol})$ was added. The mixture was stirred at $\mathrm{rt}$ for $24 \mathrm{~h}$ and then filtered over celite. Evaporation of the solvent and column chromatography of the residue (silica-gel, light petroleum/acetone 4/1) gave the perfluoroacylated porphyrin which was further purified by dissolution in AcOEt $(10 \mathrm{ml})$ and reprecipitation by addition of toluene $(0.18 \mathrm{~g}$, yield $=40 \%)$. ${ }^{1} \mathrm{H}$ NMR (acetone- $\left.\mathrm{d}_{6}\right) \delta=-2.38(\mathrm{~s}, 2 \mathrm{H}), 8.54(\mathrm{~s}$, $8 \mathrm{H}$ ), $9.03(\mathrm{~s}, 8 \mathrm{H}), 11.12$ (br s, $4 \mathrm{H}$ ); ${ }^{19} \mathrm{~F} \mathrm{NMR}$ (acetone-d 6 , ext. ref. $\left.\mathrm{CFCl}_{3}\right) \delta=-80.6(\mathrm{t}, J=9 \mathrm{~Hz}, 3 \mathrm{~F}$ ), $-118.5(\mathrm{t}, J=13 \mathrm{~Hz}, 2 \mathrm{~F}),-120.9(\mathrm{~m}, 2 \mathrm{~F}),-121.4(\mathrm{~m}, 2 \mathrm{~F}),-121.6(\mathrm{~m}, 2 \mathrm{~F}),-122.2(\mathrm{~m}, 2 \mathrm{~F}),-125.7(\mathrm{~m}, 2 \mathrm{~F})$; UV-Vis $\left(\mathrm{Et}_{2} \mathrm{O}\right) \lambda_{\max }(\log \varepsilon)=419 \mathrm{~nm}(5.42) ; \mathrm{MS}\left(\mathrm{FAB}^{+}\right) \mathrm{m} / \mathrm{z} 2534$; Anal. Calcd for $\mathrm{C}_{76} \mathrm{H}_{22} \mathrm{Cl}_{8} \mathrm{~F}_{60} \mathrm{~N}_{8} \mathrm{O}_{4}$ : C, $35.99 ; \mathrm{H}, 0.87 ; \mathrm{N}, 4.42 ; \mathrm{F}=44.99$. Found: $\mathrm{C}, 35.61 ; \mathrm{H}, 0.65 ; \mathrm{N}, 4.57 ; \mathrm{F}=45.14$.

5,10,15,20-tetrakis-12,6-dichloro-3-(n-perfluorooctacarbamoyl)phenyl/porphyrin (2). This compound was synthesized starting from porphyrin 7 according to the procedure described for 1 (column chromatography: silica-gel, $\mathrm{CH}_{2} \mathrm{Cl} 2 /$ light petroleum $4 / 1$, mixture of atropoisomers, yield $\left.=80 \%\right) .{ }^{1} \mathrm{H} \mathrm{NMR}\left(\mathrm{CDCl}_{3}\right) \delta=-2.60$ (s, 2H), 3.35-3.47 (br s, $4 \mathrm{H}), 7.62-7.83(\mathrm{~m}, 8 \mathrm{H}), 9.03(\mathrm{~s}, 8 \mathrm{H}) ;{ }^{19} \mathrm{~F} \mathrm{NMR}\left(\mathrm{CDCl}_{3}\right.$, ext. ref. $\left.\mathrm{CFCl}_{3}\right) \delta=-81.2$ $(\mathrm{t}, J=9 \mathrm{~Hz}, 3 \mathrm{~F}),-119.7(\mathrm{t}, J=14 \mathrm{~Hz}, 2 \mathrm{~F}),-121.9(\mathrm{~m}, 2 \mathrm{~F}),-122.5(\mathrm{~m}, 4 \mathrm{~F}),-123.2(\mathrm{~m}, 2 \mathrm{~F}),-126.6(\mathrm{~m}, 2 \mathrm{~F})$; UV-Vis $\left(\mathrm{Et}_{2} \mathrm{O}\right) \lambda_{\max }(\log \varepsilon)=415 \mathrm{~nm}(5.45) ; \mathrm{MS}\left(\mathrm{FAB}^{+}\right) \mathrm{m} / \mathrm{z} 1265\left(\mathrm{MH}_{2}^{++/ 2}\right)$; Anal. Calcd for $\mathrm{C}_{76} \mathrm{H}_{22} \mathrm{Cl}_{8} \mathrm{~F}_{60} \mathrm{~N}_{8} \mathrm{O}_{4}: \mathrm{C}, 35.99 ; \mathrm{H}, 0.87 ; \mathrm{N}, 4.42 ; \mathrm{F}=44.99$. Found: $\mathrm{C}, 35.74 ; \mathrm{H}, 0.92 ; \mathrm{N}, 4.20 ; \mathrm{F}=44.67$.

$M n(I I I)-\{5,10,15,20$-tetrakis-/2,6-dichloro-4-(n-perfluorooctacarbamoyl)-phenyl/porphyrin\}chloride (Mn1). A solution of porphyrin $1(0.14 \mathrm{~g}, 0.05 \mathrm{mmol})$ in DMF $(5 \mathrm{ml})$ was stirred under reflux with $\mathrm{Mn}(\mathrm{OAc}) 2.4 \mathrm{H}_{2} \mathrm{O}(0.05 \mathrm{mg}, 0.22 \mathrm{mmol})$ for $7 \mathrm{~h}$. After evaporation of the solvent in vacuo, the residue was dissolved in MTBE $(100 \mathrm{ml})$ and washed with water $(2 \times 15 \mathrm{ml})$ and saturated aqueous $\mathrm{NaCl}(2 \times 15 \mathrm{ml})$. UV-Vis spectroscopy showed the complete absence of non metallated porphyrin, whereas the presence of two minor spots was detected by thin-layer chromatography (silica-gel, $\mathrm{CH}_{2} \mathrm{Cl}_{2} / \mathrm{MeOH} 9 / 1$ ). In addition to the expected molecular ion $(\mathrm{m} / \mathrm{z}=2587)$, mass spectrometry $\left(\mathrm{MS}-\mathrm{FAB}^{+}\right)$showed the presence of peaks corresponding to the loss of one and two perfluoroacyl tails $\left(\mathrm{M}^{+}-397, \mathrm{M}^{+}-794\right)$. A portion of the crude complex $(0.08 \mathrm{mg}, 0.03$ mmol) was treated with $n$-perfluorooctanoyl chloride $(0.13 \mathrm{~g}, 0.3 \mathrm{mmol})$ as described for porphyrin 1 . Column chromatography (silica-gel, $\mathrm{CHCl}_{3} / \mathrm{MeOH} 9 / 1$ ) afforded a dark brown powder that was dissolved in MTBE (50 $\mathrm{ml}$ ) and stirred with a saturated $\mathrm{NaCl}$ aqueous solution $(50 \mathrm{ml})$. The organic phase was dried over $\mathrm{MgSO}_{4}$ and the solvent evaporated, affording pure $\mathrm{Mn}-1\left(0.04 \mathrm{~g}\right.$, overall yield $=36 \%$ ). UV-Vis (AcOEt) $\lambda_{\max }(\log \varepsilon)=474$ $\mathrm{nm}$ (5.13); MS $\left(\mathrm{FAB}^{+}\right) \mathrm{m} / \mathrm{z} 2587$; Anal. Calcd for $\mathrm{Mn}\left(\mathrm{C}_{76} \mathrm{H}_{20} \mathrm{Cl}_{8} \mathrm{~F}_{60} \mathrm{~N}_{8} \mathrm{O}_{4}\right) \mathrm{Cl}$ : C, 34.81; H, 0.77; N, 4.27; F $=43.45$. Found: $\mathrm{C}, 34.40 ; \mathrm{H}, 0.92 ; \mathrm{N}, 4.35 ; \mathrm{F}=43.06$.

Mn(III)-\{5,10,15,20-tetrakis-12,6-dichloro-3-(n-perfluorooctacarbamoyl)-phenyl/porphyrin\}chloride (Mn2). This compound was synthesized starting from porphyrin 2 according to the procedure described for Mn-1 (mixture of atropoisomers, overall yield $=74 \%$ ). UV-Vis $\left(\right.$ AcOEt) $\lambda_{\max }(\log \varepsilon)=471 \mathrm{~nm}(5.11) ; \mathrm{MS}\left(\mathrm{FAB}^{+}\right.$) 
$\mathrm{m} / \mathrm{z}$ 2587; Anal. Calcd for $\mathrm{Mn}\left(\mathrm{C}_{76} \mathrm{H}_{20} \mathrm{Cl}_{8} \mathrm{~F}_{60} \mathrm{~N}_{8} \mathrm{O} 4\right) \mathrm{Cl}: \mathrm{C}, 34.81 ; \mathrm{H}, 0.77 ; \mathrm{N}, 4.27 ; \mathrm{F}=43.45$. Found: $\mathrm{C}$, $35.74 ; \mathrm{H}, 0.92 ; \mathrm{N}, 4.20 ; \mathrm{F}=44.67$.

\section{General Procedure for Alkene Epoxidation.}

Reactions were carried out in a $20 \mathrm{ml}$ flask equipped with a teflon lined screw cap and magnetic stirrer, thermostatted at $0 \pm 0.2^{\circ} \mathrm{C}$ with circulating ethanol by a Haake F3 Cryostat. Stirring was maintained at the maximal rate achievable $(1300 \pm 50 \mathrm{rpm})$ in order to ensure the best contact between the organic and the aqueous phase. The flask was charged with: (i) $1 \mathrm{ml}$ of a $2 \cdot 0 \cdot 10^{-4} \mathrm{M}$ solution of $\mathrm{Mn}$ (III)-porphyrin in the proper organic solvent; (ii) $1 \mathrm{ml}$ of a $0.2 \mathrm{M}$ solution of alkene in the same solvent, containing tetradecane $(0.025 \mathrm{M})$ as internal standard for gas-chromatography; (iii) $10 \mu \mathrm{l}$ of a $4.0 \cdot 10^{-2} \mathrm{M}$ solution of $\mathrm{N}$-hexylimidazole in $\mathrm{CH}_{2} \mathrm{Cl}_{2}$. The solution was stirred $5 \mathrm{~min}$ then $0.86 \mathrm{ml}$ of $\mathrm{NaOCl} 0.7 \mathrm{M}$ were added to the flask. The $\mathrm{pH}$ of $\mathrm{NaOCl}$ was previously adjusted to 10.0 with solid $\mathrm{NaHCO}_{3}$. The mixture was stirred and samples were taken at different times and analysed by G.C.

Acknowledgements. The authors wish to thank the "Progetto Strategico Tecnologie Chimiche Innovative", C.N.R. Roma, for financial support.

\section{REFERENCES AND NOTES}

1. Slinn, D. S. L., Green, S.W., in Preparation, Properties and Industrial Applications of Organofluorine Compounds; Banks, R. E., Ed.; Ellis Horwood Ltd.: Chichester, 1982; p 45.

2. Zhu, D.-W., Synthesis 1993, 953.

3. Nakamura, T., Yabe, A., Chem. Lett. 1995, 533.

4. Pereira, S. M., Sauvage, G. P., Simpson, G. W., Synth. Commun. 1995, 25, 1023.

5. Klement, I., Knochel, P., Synlett. 1995, 1113.

6. Horváth, I. T., Rábai, J., Science 1994, 266, 72.

7. Meunier, B., in Metalloporphyrins catalyzed oxidations, Montanari, F., Casella, L., Eds.; Kluwer: Dordrecht, 1994, p 1.

8. Gassman, P. G., Ghosh, A., Almlöf, J., J. Am. Chem. Soc. 1992, 114, 9990 and references cited therein.

9. Wijesekera, T. P., Lyons, J. E., Ellis, P. E., Catalysis Lett. 1996, 34, 69.

10. Banfi, S., Mandelii, R., Montanari, F., Quici, S., Gazz. Chim. Ital. 1993, 123, 409.

11. Ghosh, A., J. Am. Chem. Soc. 1995, 117, 4691.

12. (a) Barkigia, K. M., Berber, M. D., Fayer, J., Medforth, C. J., Renner, M. W., Smith, K. M., J. Am. Chem. Soc. 1990, 112, 885; (b) Ochsenbein, P., Ayougou, K., Mandon, D., Fischer, J., Weiss, R., Austin, R. N., Jayaraj, K., Gold, A., Terner J., Fayer, J., Angew. Chem., Int. Ed. Engl. 1994, 33, 348.

13. (a) Montanari, F., Penso, M., Quici, S., Viganò, P., J. Org. Chem. 1985, 50, 4888; (b) Banfi, S., Montanari F., Quici, S., Recl. Trav. Chim. Pays-Bas 1990, 109, 117.

14. Lindsey, J. S., Wagner, R., J. Org. Chem. 1989, 54, 828. 
15. Anelli, P. L., Banfi, S., Legramandi, F., Montanari, F., Pozzi, G., Quici, S., J. Chem. Soc., Perkin Trans. 1 1993, 1345.

16. DiMagno, S. G., Williams, R. A., Therien, M. J., J. Org. Chem. 1994, 59, 6943.

17. Adler, A. D., Longo, F. P., Kampas, F., Kim, J., J. Inorg. Nucl. Chem. 1970, 32, 2443.

18. Granados, A., de Rossi, R. H., J. Am. Chem. Soc. 1995, 117, 885.

19. Grosse, A. V., Cady, G. H., Ind. Eng. Chem. 1947, 39, 3690.

20. Banfi, S., Pozzi, G., Quici, S., Gazz. Chim. Ital. 1993, 123, 597.

21. Mn-8 was synthesized following the same pathway outlined for the preparation of $\mathrm{Mn}-1$ and $\mathrm{Mn}-2$. Further acylation after Mn insertion was not required.

22. Synthesis of 2,6-dichloro-4-nitrobenzaldehyde will be published elsewhere.

(Received in UK 20 June 1996; accepted 18 July 1996) 